\title{
Desafíos de una práctica ético-política. El trabajo social chileno post-dictadura ${ }^{1}$
}

\author{
Luis Vivero Arriagada \\ Universidad Católica de Temuco (UCT)
}

\section{Desafíos de una práctica ético-política. El trabajo social chileno post-dictadura}

Resumen: El supuesto que se plantea para este trabajo sostiene que el Trabajo Social se ha visto dominada por la lógica mercantilista del neoliberalismo, impuesta durante la dictadura cívico-militar en Chile. Desde una perspectiva hermenéutica-crítica se analizan e interpretan los antecedentes históricos del Trabajo Social chileno. Se concluye que la formación y la práctica de la disciplina requieren de una re-orientación, que debe partir de una profunda reflexión histórica crítica y a partir de ello, generar las bases del nuevo proyecto ético- político que oriente el quehacer disciplinario y profesional.

Palabras claves: Trabajo social. Neoliberalismo. Post-dictadura. Proyecto ético-político.

\section{Desafios de uma prática ético-política: o Serviço Social chileno pós-ditadura}

Resumo: A suposição proposta para este trabalho argumenta que o Serviço Social tem sido dominado pela lógica mercantilista do neoliberalismo, imposta durante a ditadura civil-militar no Chile. Os antecedentes históricos do Serviço Social chileno são analisados e interpretados a partir de uma perspectiva hermenêutico-crítica. Conclui-se que a formação e a prática da disciplina requerem uma reorientação, a qual deve partir de uma profunda reflexão histórico-crítica, e com base nisso, gerar os fundamentos para um novo projeto ético-político que oriente o trabalho disciplinar e profissional.

Palavras-chave: Serviço Social. Neoliberalismo. Pós-ditadura. Projeto ético-político.

\section{Challenges to an Ethical-Political Practice: Chilean social work after the dictatorship}

Abstract: The study is based on the hypothesis that social work has been dominated by a mercantilist logic of neoliberalism, which was imposed during the civil-military dictatorship in Chile. It analyzes and interprets the historic antecedents of Chilean social work from a critical-hermeneutic perspective. It concludes that education and practice of the discipline require a re-orientation, which should be based on a profound critical historic reflection and based on this, generate the bases for a new ethical-political project to guide the disciplinary and professional work.

Keywords: Social work. Neoliberalism. Post-dictatorship. Ethical-political project. 


\section{Introducción}

Dice la historiadora chilena María Angélica Illanes (2016), que hubo una época en Chile en que los habitantes de todos los estamentos, especialmente los populares, se movilizaban y congregaban. Fue el afamado tiempo de la participación popular, cuando desde todos los flancos civiles, como también gubernamentales y eclesiales, se empujaba en ese camino.

Respecto de lo que ocurrió en la década del sesenta y hasta inicios de los años setenta, la historiadora se pregunta, ¿qué transformaciones produjo la política de participación y organización popular en el campo de los saberes y prácticas de intervención social, específicamente del Servicio Social chileno de los años sesenta? Esta pregunta la hace a propósito del proyecto de promoción popular llevado a cabo desde el estado en esas décadas. Aquello fue impulsado por el gobierno de Eduardo Frei Montalva (1964-1970) y luego profundizado bajo la consigna de poder popular, en el Gobierno de la Unidad Popular encabezado por Salvador Allende Gossens (1970-1973). Esta pregunta se genera porque hubo un contexto socio-político particular, el cual a su vez se materializa en una dimensión ético-política y epistemológica en la formación y práctica del Trabajo Social chileno.

Tomándonos de aquello que plantea Illanes (2016), nos preguntamos ¿de qué forma las transformaciones políticas en el contexto post-dictadura se expresan en los saberes y prácticas del Trabajo Social chileno? ¿Existen las condiciones para un proyecto ético político del Trabajo Social, como una antítesis a lo impuesto por la ideología neoliberal y sus diversas manifestaciones de idolatría al individualismo? No es fácil asumir estas preguntas, cuando en los espacios de discusión sobre la disciplina en general y en los espacios de ejercicio profesional, no se quiere asumir ciertas debilidades que se han acentuado, a consecuencia de las lógicas impuestas por el neoliberalismo. No se trata solo de hablar en términos abstractos del individualismo como el cemento ideológico del neoliberalismo, sino cómo ello se manifiesta en diferentes formas del ser y del quehacer de la disciplina.

El pragmatismo tecno-burocrático, bajo los marcos lógicos que estructuran las intervenciones, el telos de la acción profesional, pareciera ser no más que la cuantificación de ciertas metas. Ahí la reflexión profunda sobre los elementos estructurales que determinan los fenómenos sociales, resulta un obstáculo que solo genera una pérdida de tiempo, cuando de lo que se trata es de cumplir con aquella meta que se debe registrar en una determinada planilla o un software de la institución respectiva.

Quienes se niegan a ser parte de este análisis sobre los fundamentos ideológicos que hoy tiene al Trabajo Social chileno en una inercia intelectual/práctica, es porque les ha resultado funcional a sus intereses individuales, la forma en como se ha simplificado el quehacer profesional. Esto se ha traducido en una suerte de desintelectualización de la profesión, lo cual es un camino muy peligroso, pues no solo con ello se está refrendando lo que bajo otros fundamentos, se determinó con el Decreto con Fuerza de Ley (DFL) n ${ }^{\circ} 1 / 1981$ que deja a la disciplina fuera de la exclusividad universitaria (CHILE, 1981). Esta inercia intelectual, esta ausencia de la reflexión y análisis crítico, reduce la disciplina a una condición meramente técnica-instrumental, y funcional a los intereses de las elites.

Bajo este escenario, es fundamental re-pensar un proyecto ético-político del Trabajo Social chileno. Pero para que ello se genere, es imprescindible partir por una necesaria y profunda reflexión disciplinaria, que implique entre otros aspectos, una mirada histórica crítica, que permita develar los tránsitos epistémico-políticos de la disciplina, y las implicancias del régimen dictatorial en los espacios de formación y de acción disciplinaria y profesional.

Desde el punto de vista metodológico este trabajo se orienta desde una perspectiva hermenéuticocrítica. Por tanto, entendemos que la unidad teoría y práctica es la síntesis de la situación histórico-social, que nos permite la comprensión de la totalidad (FREIRE, 2006; GRAMSCI, 2006, 2012; LUKÁCS, 2013). Se realiza un análisis articulando preferentemente con referentes de distintas orientaciones teóricas marxistas. Particularmente ilustrativos son los aportes de Gramsci y Lukács, y en el campo específico del Trabajo Social, Yolanda Guerra, Marilda Iamamoto, Carlos Montaño y José Paulo Netto. Con ciertas coincidencias, diferencias y distancias con los/as anteriores, también han sido importantes para este trabajo, lo desarrollado por Teresa Matus. Tenemos claro que tienen puntos de entrada diferentes e incluso contradictorios entre ellos/as, así como el contexto histórico en el cual generan su análisis. Sin embargo, hay ciertos puntos de encuentros, respecto de las consecuencias del modelo de acumulación capitalista, el cómo se desarrolla y/o se manifiesta en el campo disciplinario. Por último, también con una inspiración proveniente del marxismo y otras perspectivas de corte humanista y crítica, tomamos los aportes de Paulo Freire, en cuanto a las prácticas de dominación, expresada entre otros aspectos, en la contradicción oprimido/opresor. Dicho lo anterior, el esquema metodológico se basó esencialmente de la siguiente forma: primero, una revisión documental (antecedentes centrado en el análisis de 
los contextos socio-históricos en el desarrollo de la profesión); en segundo lugar, análisis reflexivo crítico, en relación a la condición actual de la disciplina, en el marco del capitalismo neoliberal. Ello nos permitió instalar una discusión respecto de las contradicciones y tensiones vinculadas al proceso de construcción histórica de la disciplina, para luego dar paso a un análisis en torno a la formación y ejercicio profesional cotidiano en el campo de las instituciones en que se operacionalizan las políticas sociales. Y por último, a modo de síntesis, exponemos los desafíos y las posibilidades de generar un proyecto ético y político del Trabajo Social.

Habiendo contextualizado ciertos elementos históricos y políticos, que iluminan el análisis respecto de los desafíos de un proyecto ético político disciplinario, como también el proceso metodológico que ha sustentado este trabajo, pasamos a explicar brevemente cómo está organizado este artículo. En lo que sigue, se presentan antecedentes y análisis de lo que ha sido la instauración de la lógica mercantil en la educación y cómo ello se materializa en el Trabajo Social chileno. Luego, se centra un análisis con sus respectivos antecedentes de la formación y práctica disciplinaria bajo hegemonía política, económica y cultural del neoliberalismo. Por último, a modo de síntesis final, se proponen una discusión sobre los desafíos en la formación y acción praxiológica, que permitiría generar un nuevo proyecto ético y político del Trabajo Social en Chile post-dictadura.

\section{La educación de mercado. El legado de la dictadura pinochetista}

El 11 de septiembre 1973 es una fecha que para Chile y América Latina no puede pasar inadvertida. El Golpe de Estado perpetrado por todas las ramas de las Fuerzas Armadas y Carabineros de Chile, con la complicidad y apoyo de la elite política y económica, permitirá la instauración de una dictadura cívico-militar de diecisiete años. Estos hechos son imposibles dejarlos fuera, si queremos hacer un análisis de la sociedad actual y en particular de la disciplina/profesión del Trabajo Social, en tanto campo de formación y práctica políticotécnico-intelectual.

Es así que con el Golpe de Estado de 1973, la historia del Trabajo Social y la sociedad en su conjunto sufrirán un profundo quiebre, un cambio radical (ALAYÓN, 2005; HERNÁNDEZ; RUZ, 2005; RUZ, 2016; VIDAL, 2016). Los espacios y las posibilidades de construcción de conocimiento no solo se vieron limitados, sino que además intervenidos por los militares y los intelectuales orgánicos del nuevo bloque histórico. Los limitados campos de formación se convirtieron en un espacio para impulsar una reforma cultural y moral (GRAMSCI, 1967, 2006, 2012; MASSARDO, 2012). Los grupos dominantes impusieron esta nueva visión de mundo, que tuvo como cemento ideológico el neoliberalismo, el cual sin duda permeabilizó el campo disciplinario y sus formas de operacionalizar estos nuevos marcos epistémico-político (VIDAL, 2016; VIVERO, 2013, 2016).

No está demás reiterar que todo el ímpetu crítico y el ethos transformador que se estaba impulsando desde el movimiento de Reconceptualización, tuvo un término abrupto, y con las consecuencias políticas y humanas para aquellos y aquellas que se situaron bajo esa nueva concepción del Trabajo Social. El retroceso en términos teóricos y metodológicos, y la fuerza reflexiva que se había instalado, se tradujo en un retroceso, que hasta hoy no se ha logrado recuperar (MATUS, 2016; VIVERO, 2016).

Este retroceso teórico-metodológico en el campo de la disciplina, entre otras cuestiones se traduce en la re-instalación de las lógicas de intervención de tipo asistencialistas y tecnocráticas, las cuales, se pensaba, habían sido superadas con el proceso reconceptualizador. En otros ámbitos, este nuevo escenario implicó el cierre de las carreras y los y las profesionales sufrieron las atrocidades de la dictadura, en términos de violación a sus derechos fundamentales (ALAYÓN, 2005; HERNÁNDEZ; RUZ, 2005). Un ejemplo de este oscuro periodo es relatado con mucho sentimiento por una de sus protagonistas:

El 12 de septiembre de 1973 la Escuela (de la Universidad de Chile) sufrió el brutal allanamiento de las Fuerzas Militares. Grandes fogatas quemaron todo lo que encontraron a su paso: libros, documentos y trabajos de estudiantes y profesores. Solo se llevaron las mercaderías que, recientemente, se habían comprado para el casino de los estudiantes. (SEPÚLVEDA, 2016, p. 142).

Este hecho que relata Sepúlveda, solo será el inicio de un largo invierno para Chile y para el Trabajo Social. Bajo este duro escenario, es fundamental reconocer y valorar la valentía de un grupo significativo de profesionales, que desde los primeros años de la dictadura, se volcaron a un trabajo en defensa de los Derechos Humanos. En estas experiencias, cabe destacar aquellas acciones en el marco de la Vicaría de la Solidaridad y La Corporación de Promoción y Defensa de los Derechos del Pueblo (CODEPU) (ALAYÓN, 2005; HERNÁNDEZ; RUZ, 2005; RUZ, 2016; SEPÚLVEDA, 2016).

Pero las elites y los intelectuales orgánicos, intentarán con todos los medios que tienen a su disposición, crear una fantasía cotidiana que parezca que se vive en la absoluta normalidad. Poco a poco el individualismo 
y el consumismo comienzan a instalarse en las conciencias y las prácticas cotidianas del pueblo chileno. En el campo del Trabajo Social, este nuevo escenario se irá cimentando bajo las nuevas consignas que impone la ideología neoliberal. Los nuevos discursos pragmáticos y mercantilistas se mueven entre lo tecnocrático, la burocracia institucional y las miradas psicologistas que centrará el problema y la responsabilidad en el individuo.

Así entonces comienzan a instalarse en la sociedad neoliberal, y en particular en Chile de mediados de los años setenta del siglo veinte, lo que se denominaría la mercantilización de la vida (BORON, 2000, 2003; GARRETÓN, 2000, 2014; LARRAÍN, 2005; MOULIAN, 1997, 2009). De esta manera las escuelas toman posiciones contradictorias, disputadas por el poder y el saber, que se orientan a mantener el orden establecido, basadas en una ideología que define la educación como un bien de consumo.

El terrorismo de estado permitió la instalación de este nuevo sistema articulado en torno a un mercado oligopolizado que transforma nuestra sociedad en un gran monopolio (MASSARDO, 2012; MOULIAN, 1997, 2009). Asimismo, durante los años de dictadura cívico-militar, se logró un inusitado disciplinamiento de las fuerzas de trabajo y de las clases subalternas en general. De esta forma, la dictadura instala en el sentido común, el discurso del miedo, la idolatría al éxito individual y al consumo desmedido como el modus vivendi del pueblo chileno. Un nuevo sentido común que será la expresión material y simbólica de la consolidación de una nueva hegemonía (GRAMSCI, 1981, 2006, 2012; MASSARDO, 2012).

En los años ochenta del siglo veinte, las condiciones materiales y subjetivas ya estaban plenamente instaladas en la sociedad chilena. La dictadura desplegaba todo su control político y cultural en la sociedad chilena, sumado a una constante represión en los sectores populares y grupos opositores (MOULIAN, 1997, 2009). Este escenario sin duda va a generar transformaciones en la disciplina en diferentes sentidos.

En términos materiales, la disciplina se verá fuertemente dañada, con la eliminación de su exclusividad universitaria. El Decreto con Fuerza de Ley $n^{\circ} 1$ de 1981 (CHILE, 1981) y la Ley n ${ }^{\circ} 18.962$ Orgánica Constitucional de Educación - LOCE (CHILE, 1990), serán los instrumentos que, por un lado le quitan la exclusividad universitaria a la profesión, y por otro, permiten una explosión en ofertas académicas de nivel superior. Así entonces, la creación de Institutos Profesionales y Universidades privadas, será determinante para la consolidación de mercantilización de la profesión (VIVERO, 2010, 2016). De esta forma, Trabajo Social se convertirá en una de las carreras que tendrá una importante oferta en las instituciones privadas (universidades e institutos profesionales), reflejando el lucro en la educación (SARAVIA, 2015; SUÁREZ, 2012).

Por su parte, los Decretos Ley no 2.757 de 1979 (CHILE, 1979) y no 23.163 de 1980 (CHILE, 1980), definieron nuevos lineamientos en relación a la conformación de los colegios profesionales, reconfigurando su estructura organizacional y legal. Ello se tradujo en que el Colegio de Asistentes Sociales perdió la tutela del colectivo profesional.

La lógica neoliberal en términos materiales se instalará en el campo de la educación, transformando los intereses sociales en bienes de consumo, donde los grandes beneficiados serán las instituciones privadas. La década del ochenta del siglo pasado, es el contexto en el cual la mercantilización de la educación se materializó gracias a las condiciones políticas imperantes (SARAVIA, 2015; SUÁREZ, 2012). En el campo disciplinario esto no solo se tradujo en una expulsión de la oferta académica, sino que también en la instalación de carreras con equipos académicos con una notoria asimetría en sus niveles de especialización y formación de postgrado (MATUS, 2016). Todo esto es factible, dado que se cuenta con el respaldo político, institucional y jurídico. Instrumentos legales, como el Decreto con Fuerza de Ley $n^{\circ}$ 1, serán garantes de esta libertad académica de las universidades, tal cual se expresa en su artículo $5^{\circ}$ :

La libertad académica incluye la facultad de abrir, organizar y mantener establecimientos educacionales, cumpliendo los requisitos establecidos por la ley, y la de buscar y enseñar la verdad conforme con los cánones de la razón y los métodos de la ciencia (CHILE, 1981).

En consecuencia, coincidimos con Gaudichaud, en que se produjo una masificación real y acelerada de diplomas en Chile. Un mercado educacional desmedido, de baja calidad y que se sostiene en gran medida en base al endeudamiento de los jóvenes y sus familias. A diferencia de lo que ocurría hasta el año 1973, Gaudichaud $(2015$, p. 84$)$ nos ilustra de manera muy clara con lo siguiente:

Hasta el golpe de 1973, la educación chilena era reconocida por su calidad y gratuidad. Actualmente, el Estado sólo dedica el 4,4\% del PIB a la educación (cifra más baja de la OCDE), bien lejos de 7\% recomendada por la UNESCO, mientras que solo el $16 \%$ del sistema educativo superior es financiado por fuentes públicas.

A más de un cuarto de siglo del retorno a la democracia, y cerca de cuarenta años de la imposición del neoliberalismo, en términos estructurales el escenario no ha cambiado substancialmente en relación a lo 
implementado en dictadura. En el campo de la educación se han derogado algunos cuerpos legales como el DFL $n^{\circ} 1$ (CHILE, 1981) y la LOCE (CHILE, 1990). Se ha restituido el rango universitario del Trabajo Social. Sin perjuicio de ello, la lógica de mercado en la educación no se ha superado. Parafraseando a Moulian (1997), en el Chile actual existe un número no menor de instituciones que imparten la carrera de Trabajo Social o Servicio Social. Los datos del Ministerio de Educación ${ }^{2}$ muestran que al año 2016 exístían 91 instituciones de educación superior que impartían esta profesión. Tales datos nos indican que el $80,2 \%$ de la oferta de estos programas, se imparten en instituciones privadas. El 13\% de la oferta corresponde a universidades estatales y el 9,8\% universidades privadas con aporte estatal, las cuales pertenecen al Consejo de Rectores de Universidades de Chile (CRUCH).

En este contexto de mercantilización de la educación, cabe destacar que existen instituciones privadas que tienen entre 10 y 14 programas a nivel nacional. Estas se imparten en la Universidad Santo Tomás y la Universidad Tecnológica de Chile (INACAP) respectivamente (VIVERO, 2016). La sobre oferta de programas académico es evidente, lo cual además genera una asimetría en la calidad de la formación, tanto entre las mismas instituciones como en relación a los CRUCH (MATUS, 2016).

De los datos señalados, se pueden desglosar otros antecedentes más específicos, que dan cuenta que al año 2016, en Chile se existía un total de 124 programas de Trabajo Social impartidos ya sea por Universidades o por Institutos profesionales. Esto solo al considerar aquellos en modalidad presencial, pues existe una cifra importante de programas en modalidad continuidad de estudios, programas especiales o semi-presenciales. Si sumamos este tipo de programas, la cifra aumenta a 304 programas, según datos del Ministerio de Educación de Chile ${ }^{3}$. Este sistema de educación mercantil instaurada durante la dictadura cívico-militar hasta hoy no ha tenido mayores cambios.

Hay que tener en consideración además, que no se trata solo de una cuestión de sobre oferta - que por cierto es negativo - sino que la instalación de una hegemonía de concepciones epistémico-políticas y teóricas, que responden a los intereses de las clases dominantes. Aquellas instituciones de carácter privado se sostienen como tal, porque la educación es definida como una mercancía.

En este escenario de mercantilización de la educación chilena, nos preguntamos hasta dónde, en aquellas instituciones privadas (e incluso públicas), se está dispuesto a sostener praxiológicamente un proyecto ético político que sustenten los procesos formativos del Trabajo Social. Un proyecto ético y político que apueste por la transformación de las estructuras sociales, políticas y económicas capitalistas. Si fuese así, esto debería materializarse en los campos de acción profesional. Pero aquí consideramos que se presenta otro obstáculo: las instituciones, sus equipos profesionales y sus prácticas, están determinados por el contexto histórico-político, y por lo mismo, por la hegemonía de una concepción instrumental, tributaria al neoliberalismo. Por lo tanto, cualquier transformación no será posible sino producto de una lucha ideológica y material en el campo académico articulado con espacios de actuación profesional.

\section{La formación y práctica del Trabajo Social chileno en clave neoliberal}

Coincidimos con Yolanda Guerra, al señalar que las transformaciones macro-sociales producen alteraciones en las demandas profesionales. En consecuencia, en el campo del Trabajo Social se genera una "redefinición de los objetos de intervención, atribuyen nuevas funciones a la profesión y nuevos criterios para la adquisición de nuevas legitimidades" (GUERRA 2015, p. 84). Pero esta redefinición, consideramos que en gran medida ha estado determinada por la expansión de la oferta de formación académica, y fundamentalmente la lógica mercantil instrumental, impuesta por la ideología neoliberal. En el caso de Chile en particular, ha significado una cierta hegemonía de formas irreflexivas y acríticas al momento de enfrentar una intervención social, dado que los marcos referenciales que sustentan la acción profesional, responden más bien a una acción de tipo instrumental, tributaria del modo de producción capitalista neoliberal (AGUAYO, 2007; WEBER, 2004). Debe tenerse presente, que en este contexto, la retórica crítica del Trabajo Social obedece más bien a un discurso propagandístico, en donde los conceptos críticos responden más bien a un marketing educacional y social. Este discurso crítico estaría vacío del contenido político, que es propia la concepción de la praxis emancipadora, que sustenta dicha perspectiva (NETTO, 2012; GUERRA, 2015; IAMAMOTO, 1992).

En consecuencia, la matriz ideológica neoliberal no solo ha implicado la expansión de la oferta académica, lo cual es una expresión material de su hegemonía. Sino que por sobre todo, que su peso discursivo, radica en la instalación de un lenguaje que emana desde la elite intelectual, y que no busca sino la producción y reproducción de valores y conductas acorde a sus intereses (GRAMSCI, 1967, 2006, 2012; GUERRA, 2015; IAMAMOTO, 1997; VIVERO, 2013, 2016).

Ergo, es de suyo coherente, que en el Trabajo Social se instale el sentido común en un nivel hegemónico, pues con ello invisibiliza esta condición subalterna, las posibilidades de una comprensión de la totalidad histórica 
del sistema y la naturaleza de sus contradicciones y desigualdades. Esto es coherente con análisis que se desprenden de algunos autores/as marxianos/as, a pesar de su distancia temporal y sus particularidades teóricas (GUERRA, 2015; IAMAMOTO, 1997; MASSARDO, 2012).

En consecuencia, al no sostenerse en un proyecto ético-político y crítico, coherente y pertinente al contexto histórico y estructural, se está más bien respondiendo mecánicamente a los intereses de las clases dominantes, representadas en las estructuras técnico-operativas de las instituciones que operacionalizan las diferentes políticas sociales. Los discursos cargados de sentido común y la práctica instrumental, irreflexiva y acrítica, no hacen más que refrendar esto. Amparado en esta lógica, en que imparta más la forma que el fondo, no es extraño que el proceso de formación profesional, se sostenga sobre la base de declaraciones discursivas críticas.

Sin perjuicio de reconocer que no es posible que en todas las instituciones que dictan Trabajo Social, se deba asumir como paradigma la perspectiva crítica o la filosofía de la praxis, consideramos que al menos es fundamental una permanente discusión académica, que nutra de contenidos teóricos y conceptuales a la disciplina, para una mejor comprensión de la totalidad determinante de las condiciones de la vida cotidiana, en las cuales se orientan la intervención profesional y la generación de conocimientos.

En consideración a lo anterior, para que una formación en Trabajo Social responda con cierta coherencia a un proyecto ético político, y que sus perfiles de egreso tengan posibilidad de ser desarrollados en la acción profesional, deben darse ciertas condiciones. Aquí planteamos algunas que responden más bien a la instalación de una dinámica, y estructura del proceso de formación académica:

a) Nivel de especialización del cuerpo académico. Se requiere fortalecer y consolidar un cuerpo académico con formación de postgrado. Sin excluir las discusiones o investigaciones temáticas, consideramos fundamental que exista un núcleo de investigadores e investigadoras que se ocupen del campo disciplinario. Una discusión epistemológica y teórica sobre y desde los procesos de intervención y desde el campo de intervención se redimensione lo teórico-conceptual.

b) Discusiones disciplinarias del cuerpo académico. Si existe un cuerpo académico con una cierta permanencia en la universidad, posibilita que se dé una discusión, una reflexión sobre lo que se declara en el perfil, lo que se está desarrollando en el proceso formativo y su articulación con los campos de acción profesional.

c) Líneas de investigación del cuerpo académico. Si hay líneas de investigación, estas deberían tener conexión con el perfil de egreso, lo cual le de coherencia al proceso formativo. Tanto los proyectos de investigación como las líneas de investigación deben ser coherentes con el perfil, y esto articulado con los campos de ejercicio profesional.

d) Producción y democratización de conocimientos. Si se dan las tres condiciones anteriores, esto debería consolidarse en una producción de conocimientos ya sea de manera individual o colectiva. Si se pretende construir un proyecto ético y político, estos deben generarse desde una construcción colectiva.

La totalidad histórica tiene una relación dialéctica con los distintos campos de actuación en la sociedad. En este sentido, las ciencias sociales no están ajenas a las dinámicas del contexto societal. Lo que se desarrolla y cómo funciona la sociedad, tendrá una expresión material y subjetiva en el campo científico y viceversa. El Trabajo Social, desarrolla su acción en un campo de contradicciones, entre estos, está su práctica funcional con la reproducción modelo que mejor satisface las necesidades de las clases dominante y por otro lado, la defensa de derechos y conquistas sociales (GUERRA, 2015; IAMAMOTO, 1997; MATUS, 2016; MONTAÑO, 1999, 2004; NETTO, 1992, 2012). A pesar de los distintos lugares teóricos e históricos de estos/as autores/as, hay puntos de coincidencias en cuanto a la condición histórica de la disciplina.

Sin duda no podemos separar el campo disciplinario/profesional del contexto histórico-político. Hacer esta separación, significaría llevar al extremo la concepción tecnocrática e instrumental de la acción profesional. En términos ético-político, dicha separación lleva peligrosamente a ubicarnos en un nivel de complicidad en la vulneración de los derechos de los más desposeídos y desposeídas de la sociedad. Sea esto por la no reflexión que fundamentan y explican las condiciones materiales y simbólicas de la realidad en la cual se desarrolla la acción (incluyendo el contexto institucional), o cuando se tienen los elementos para conocer y explicar dichas condiciones se prefiera obviarlo y solo remitirse al cumplimiento de aquellas metas que la tecnocracia exige. En cualquiera de estas dos formas, se está transgrediendo gravemente a los aspectos éticos declarados en la propia definición de la disciplina aprobados por la Federación Internacional de Trabajo Social - FITS (2014).

\section{Desafíos para una práctica ético-política}

Si asumimos la tesis de que las clases subalternas sufren permanentemente y de diversas formas, la dominación de la clase dominante, y el Trabajo Social en tanto disciplina que tiene una relación permanente con estos sectores subalternos, es de suyo, un deber ético asumir un compromiso ético y político con esta clase 
vulnerada. En este punto nos parece relevante destacar, que a pesar de las distancias históricas, puede encontrar puntos de encuentros en los análisis y categorías desarrolladas por algunos autores como Freire (1996, 2006), Gramsci (1981, 2012), Iamamoto (1992) y Massardo (2012).

El campo de la acción profesional, brinda la posibilidad de un conocimiento in situ de las formas de vulneración que viven las clases subalternas. Esto no solo entrega un conocimiento sobre la realidad material, sino que además determina la función ético-política de la disciplina. En consideración a lo anterior, la condición de intelectual orgánico que cumple el Trabajo Social (VIVERO, 2010, 2013, 2016), no es un delirio de quienes asumen una perspectiva crítica, sino que ello se manifiesta en términos materiales y simbólicos. Esta condición de intelectual orgánico es aprovechada por las elites dominantes. Por ello es que sentido común como modus operandis del quehacer profesional, resulta beneficioso para los intereses de las elites. A menor reflexión, más sentido común, y menos compromiso ético y político.

\section{La direccionalidad de una} praxis ético-política transformadora, se hace siempre a partir de una lectura crítica de la totalidad histórica, de sus relaciones de producción y de sus condiciones determinantes. Por ello es que en un Trabajo Social que asuma una praxis emancipadora, y a partir de ello sustente su proyecto ético político, no es permisible la neutralidad bajo ningún punto de vista.
Ese sentido común se camufla en los diferentes espacios de formación y en los campos de la acciónintervención social institucionalizada. El sentido común va acuñando un discurso pragmático, con arreglo a fines instrumentales, bajo las consignas de eficiencia y eficacia. Ergo, la reflexión y discusión teórica conceptual es irrelevante, pues lo que se valora es cumplir con una meta. El discurso de los intelectuales orgánicos de las elites, diseminan su tesis de la muerte de las ideologías, la desaparición de las clases sociales, el fin de las utopías (FREIRE, 2002). Así entonces, no es extraño que en ámbitos de las instituciones que operacionalizan las distintas políticas sociales predomine una lógica puramente técnica, desvinculada de la política y de la ideología (FREIRE, 2002, 2006; GUERRA, 2015; IAMAMOTO, 1997; MATUS, 2016; NETTO, 2012).

El sentido común que operaría en la acción práctica de la profesión, no es algo casual o simplemente una cuestión de desinterés intelectual. No se explica solo como un proceso de desintelectualización disciplinaria, sino que ello es una consecuencia de la hegemonía de un proyecto ideológico, que encarna los intereses de clase. Tomemos una cita de Freire (2002, p. 29) para ilustrar esta idea: "La ideología dominante no solo opaca la realidad sino que también nos vuelve miopes para no ver claramente esa realidad. Su poder es domesticador y nos deja ambiguos e indecisos cuando somos tocados y deformados por él."

Entonces, si la ideología dominante no solo opaca la realidad sino que nos vuelve miopes, el sentido común no es solo una simple expresión de la hegemonía de la clase dominante, sino que una forma de imponer una visión de mundo. La visión de mundo de las elites y de sus intereses.

Amén de lo anterior nos preguntamos: ¿si los discursos retóricos del Trabajo Social hacen referencia a la emancipación y transformación social por qué esto no se expresa en una lectura crítica de la realidad histórica y ello no se materializa en un proyecto ético político en la formación y práctica disciplinaria-profesional? Pues bien, sentimos que dicho discurso, que apuntan a la emancipación y transformación social no son más que la reproducción de un tipo de lenguaje que responde irreflexivamente a un deber ser. Pero no necesariamente ese discurso es resultado de un profundo análisis histórico-político. Consideramos que no es coherente plantear que el Trabajo Social orienta su acción como una praxis transformadora, que su telos se orienta a la emancipación, cuando no hay un proyecto ético y político que lo sustente.

Planteamos que desde el sentido común, desde la despolitización y la neutralidad epistémico-política no se puede canalizar un proyecto transformador. Una lectura crítica de la totalidad histórica y de las condiciones materiales y simbólicas que determinan al ser social y su práctica cotidiana, nos posibilita encontrar en esta historicidad crítica, los caminos para la transformación.

No puede existir una praxis neutra y deshistorizada y menos una praxis sustentada solo desde el sentido común. La direccionalidad de una praxis ético-política transformadora, se hace siempre a partir de una lectura crítica de la totalidad histórica, de sus relaciones de producción y de sus condiciones determinantes. 
Por ello es que en un Trabajo Social que asuma una praxis emancipadora, y a partir de ello sustente su proyecto ético político, no es permisible la neutralidad bajo ningún punto de vista. Asimismo, bajo ningún punto de vista, un proyecto ético y político se sustenta desde el sentido común, deshistorizado y apolítico. Un proyecto ético-político implica opciones, rupturas, decisiones, estar a favor o en contra de ciertos proyectos de sociedad y de ciertas prácticas. He aquí la invitación a re-pensar un Trabajo Social crítico latinoamericano y caribeño, sobre la base de un compromiso ético político, que a su vez implique un proyecto ético-político que tenga como horizonte posible, la emancipación y transformación del orden capitalista.

\section{Referencias}

AGUAYO, C. Las profesiones modernas: dilemas del conocimiento y del poder. Buenos Aires: Espacio, 2007. ALAYÓN, N. (Org.). Trabajo Social latinoamericano. A 40 años de la reconceptualización. Buenos Aires: Espacio, 2005. BORON, A. Estado, capitalismo y democracia. Buenos Aires: CLACSO, 2003.

. Tras el Búho de Minerva. Mercado contra democracia en el capitalismo de fin de siglo. Buenos Aires: Fondo de Cultura Económica, 2000.

CHILE. Decreto con Fuerza de Ley n ${ }^{\circ} 1$ de 1981. Ministerio de Educación Pública de Chile. Biblioteca del Congreso Nacional, Chile. 1981. Disponible en: <https://www.leychile.cl/Navegar?idNorma=3389>. Acceso: 10 oct. 2016.

CHILE. Decreto Ley no 2.757 de 1979. Ministerio de Educación Pública de Chile. Biblioteca del Congreso Nacional, Chile. 1979. Disponible en: <https://www.leychile.cl/Navegar?idNorma=6992>. Acceso en: 25 sept. 2016.

. Decreto Ley no 23.163 de 1980. Ministerio de Educación Pública de Chile. Biblioteca del Congreso Nacional, Chile. 1980. Disponible en: <http://www.leychile.cl/Navegar?idNorma=70643>. Acceso en: 25 sept. 2016.

. Ley Orgánica Constitucional nº 18.962 del Ministerio de Educación Pública. Biblioteca del Congreso Nacional de Chile. 1990. Disponible en: $<\mathrm{http}: / /$ www.leychile.cl/N?i=30330\&f=2005-09-27\&p=>. Acceso en: 25 sept. 2016.

FEDERACIÓN INTERNACIONAL DE TRABAJO SOCIAL. Informe a la Asamblea General de la FITS 2014 sobre la Definición Global del Trabajo Social. 2014. Disponible en: <http://cdn.ifsw.org/assets/ifsw_83308-10.pdf $>$. Acceso en: 25 sept. 2016.

FREIRE, P. Cartas a quien pretende enseñar. Buenos Aires: Siglo Veintiuno, 2002.

. Pedagogía del oprimido. Buenos Aires: Siglo Veintiuno, 2006.

Politica y educación. México, D.F.: Siglo Veintiuno, 1996.

GARRETÓN, M. A. Las ciencias sociales en la trama de Chile y América Latina. Estudios sobre transformaciones sociopolíticas y movimiento social. Santiago: Editorial Lom, 2014.

. Politica y Sociedad entre dos épocas. América Latina en el cambio de siglo. Rosario: Homo Sapiens, 2000.

GAUDICHAUD, F. Las fisuras del neoliberalismo chileno. Trabajo, crisis de la "democracia tutelada" y conflictos de clase. Santiago: Quimantú y Tiempo Robado, 2015.

GRAMSCI, A. Cuadernos de la cárcel. Tomo II. México: Ediciones Era, 1981.

. La formación de los intelectuales. México D.F.: Grijalbo, 1967.

. Los intelectuales y la organización de la cultura. Buenos Aires: Nueva Visión, 2012.

. Política y sociedad. Santiago: Editorial Centro Gráfico, 2006.

GUERRA, Y. Trabajo Social: Fundamentos y contemporaneidad. Buenos Aires: Colegio de Trabajadores Sociales de la Provincia de Buenos Aires, 2015.

HERNÁNDEZ, J.; RUZ, O. La Reconceptualización en Chile. En: ALAYÓN, N. (Org.). Trabajo Social Latinoamericano. A 40 años de la Reconceptualización. Buenos Aires: Espacio, 2005. p. 85-101.

IAMAMOTO, M. Servicio Social y División del Trabajo. Un análisis crítico de su fundamento. Sao Paulo: Editorial Cortez, 1997.

ILLANES, M. A. Participación popular: una utopía política; otro Servicio Social. Chile, 1963-1965. En: VIDAL, P. (Coord.). Trabajo Social en Chile. Un siglo de trayectoria. Santiago: RIL Editores, 2016. p. 61-93.

LARRAÍN, J. ¿América Latina moderna? Globalización e identidad. Santiago: Lom, 2005.

LUKÁCS, G. Historia y conciencia de clases. Buenos Aires: Editorial R y R, 2013.

MASSARDO, J. Gramsci en Chile. Apuntes para el estudio crítico de una experiencia de difusión cultural. Santiago: Lom, 2012.

MATUS, T. Los desafíos de refundar: Paradojas de redistribución y reconocimiento en el Trabajo Social chileno. En: VIDAL, P. (Coord.). Trabajo Social en Chile. Un siglo de trayectoria. Santiago: RIL Editores, 2016. p. 293-249.

MONTAÑO, C. El servicio social frente al neoliberalismo. Cambios en su base de sustentación funcional-laboral. 1999. Disponible en: $<$ http://cuuies.fes.ucr.ac.cr/info/bitacora/logAutor.php>. Acceso en: 4 oct. 2016.

. Hacia la construcción del Proyecto Ético-Político Profesional crítico. In: SEMINARIO LATINOAMERICANO DE ESCUELAS

DE TRABAJO SOCIAL, 18., 2004, San José (Costa Rica). Anales... San José (Costa Rica): ALAETS, 2004.

MOULIAN, T. El Chile actual. Anatomía de un mito. Santiago: Lom-ARCIS, 1997.

. Contradicciones del desarrollo politico chileno, 1920-1990. Santiago: Lom, 2009.

NETTO, J. P. Capitalismo monopolista y Servicio Social. São Paulo: Cortez, 1992. 
Trabajo Social. Crítica de la vida cotidiana y método de Marx. La Plata: Productora del Boulevard, 2012.

RUZ, O. Reorientación y reconceptualización del Trabajo Social en Chile. En: VIDAL, P. (Coord.). Trabajo Social en Chile. Un siglo de trayectoria. Santiago: RIL Editores, 2016. p. 95-118.

SARAVIA, F. A. La formación de los trabajadores sociales en Chile: ¿un asunto de oferta y demanda? Cuadernos de Trabajo Social, Madrid, v. 28, n. 1, p. 69-81, 2015.

SEPÚLVEDA, L. Algunas reflexiones acerca del ejercicio profesional del Trabajo Social durante la dictadura militar. En: VIDAL, P. (Coord.). Trabajo Social en Chile. Un siglo de trayectoria. Santiago: RIL Editores, 2016. p. 141-154.

SUÁREZ, P. La formación de los trabajadores sociales en Chile. Entre el sentido de lo público y el lucro en la educación. In: SEMINARIO LATINOAMERICANO DE ESCUELAS DE TRABAJO SOCIAL, 20., 2012, Córdoba (Argentina). Anales... Córdoba (Argentina): Universidad Nacional de Córdoba, 2012.

VIDAL, P. Conservación y renovación del trabajo social chileno 1960-1973. La Escuela Dr. Lucio Córdova. En: Trabajo Social en Chile. Un siglo de Trayectoria. Santiago: RIL Editores, 2016. p. 29-60.

VIVERO, L. Hegemonía y lucha de clases en la práctica del Trabajo Social. Revista Eleuthera, Manizales (Colombia), v. 4, p. 137-152, enero/dic. 2010

. El Trabajo Social en la era neoliberal. Desafíos para una neo-reconceptualización. En: VIDAL, P. (Coord.). Trabajo Social en Chile. Un siglo de trayectoria. Santiago: RIL Editores, 2016. p. 175-195.

. El Trabajo Social y su función de intelectual orgánico. Revista Regional de Trabajo Social, Montevideo, v. 27, n. $59,2013$.

WEBER, M. La ética protestante y el espíritu del capitalismo. Buenos Aires: Ediciones Libertador, 2004.

\section{Notas}

1 Loque se presenta en estas líneas, se desprende fundamentalmente de resultados preliminares de la investigación "La formación de los trabajadores sociales en Chile: Un acercamiento interpretativo a la dimensión histórica-política de sus perspectivas teóricas”. Esta investigación es financiada por Conicyt, por medio del Proyecto Fondecyt de Iniciación n ${ }^{\circ} 11140352$.

23 Disponible en: <http://www.mifuturo.cl>. Acceso en: 25 sept. 2016.

\section{Luis Vivero Arriagada}

luisvive@gmail.com

Doctorado en Procesos Sociales y Políticos en América Latina por la Universidad de Arte y Ciencias Sociales (Universidad ARCIS)

Académico e Investigador del Departamento de Trabajo Social de la Universidad Católica de Temuco (UCT)

\section{UCT}

Manuel Montt, 56 - Edificio C, Oficina 503

Campus San Francisco, Departamento de Trabajo Social

Temuco - Araucanía - Chile 